\title{
EL MIEDO COMO ESTRATEGIA "GANADORA": EL CASO DE LA ELECCIÓN PRESIDENCIAL EN MÉXICO, 2006
}

\author{
FEAR AS A "WINNING" STRATEGY: \\ THE CASE OF PRESIDENTIAL ELECTION IN MÉXICO, 2006
}

\author{
Andrés Valdez Zepeda * \\ Delia A. Huerta Franco** \\ Octavio A. Pérez Preciado***
}

RESUMEN

En este artículo se analiza el uso del miedo como parte de las estrategias de control y manipulación política, tanto en regímenes totalitarios, autoritarios y democráticos. Asimismo, se describe el uso del miedo como parte de las estrategias usadas por partidos y candidatos durante las campañas electorales con el objetivo de ganar las elecciones. Se analiza el caso de la elección presidencial de México del 2006, en la que el miedo fue parte central del trazo estratégico para ganar la elección presidencial por parte del Partido Acción Nacional (PAN) y su candidato Felipe Calderón Hinojosa. Se concluye que en la política moderna ganará y mantendrá el poder quien sea más astuto en articular estrategias y obtener beneficios políticos, movilizando el uso del miedo de los electores.

PALABRAS CLAVE: MÉXICO * ELECCIONES * SISTEMAS POLÍTICOS * MIEDO * AMÉRICA LATINA *
ESTRATEGIAS POLÍTICAS

\section{ABSTRACT}

This article analyzes the use of fear as part of the control strategies and political manipulation, both totalitarian regimes, authoritarian and democratic. It also describes the use of fear as part of the strategies used by parties and candidates during election campaigns in order to win elections. We analyze the case of Mexico's presidential election of 2006, in which fear was central strategic stroke to win the presidential election by the National Action Party (PAN) candidate Felipe Calderon Hinojosa. The conclusion is that in modern

Centro Universitario de Ciencias Económico Administrativas de la Universidad de Guadalajara, México. azepeda@cucea.udg.mx

** Centro Universitario de Ciencias Económico Administrativas de la Universidad de Guadalajara, México. damparo@cucea.udg.mx

*** Centro Universitario de Ciencias Económico Administrativas de la Universidad de Guadalajara, México. perezoctavio2000@hotmail.com 
politics will gain and maintain power beating anyone in articulating strategies and mobilizing political gain the use of fear of the voters.

KEYWORDS: MÉXICO * ELECTIONS * POLITICAL SYSTEMS * FEAR * LATIN AMERICA * POLITICAL STRATEGIES

\section{INTRODUCCIÓN}

El miedo ${ }^{1}$ es una perturbación angustiosa del ánimo por la percepción ${ }^{2}$ del individuo sobre un riesgo o daño real o imaginario, mismo que tiene un efecto en su conducta $y$ sus sentimientos ${ }^{3}$.

Tener miedo resulta algo normal en el ser humano. De hecho, el miedo es la forma más común de organización del cerebro primario de los seres vivos. Se trata de un esquema orgánico de supervivencia, que se encuentra en la mente del individuo. Es una advertencia emocional de que se aproxima algún daño, sea este real o ficticio. De esta forma, el miedo es una emoción que sirve para iniciar el escape y/o la evitación de peligros y amenazas, reales o irreales, para asegurar la supervivencia ${ }^{4}$. Además, el miedo como emoción humana es omnipresente y está muy arraigado entre la gente.

Desde la antigüedad, el miedo se ha usado como instrumento de control, dominación y movilización política por parte de las elites y grupos gobernantes. Primero, fue el miedo a la furia de los dioses, a la ira de la naturaleza $y$ las pestes por las destrucciones $y$

1 El término miedo se usa comúnmente, como sinónimo de temor, fobia, horror, pánico o terror, aunque estos son proporcionalmente diferentes, ya que cada uno de los términos implican un estado de perturbación emocional distinto en grado, nivel $y$ magnitud.

De acuerdo con Elizabeth, Lira Kornfeld (1991), el miedo se refiere a vivencias desencadenadas por la percepción de un peligro cierto o impreciso, actual o probable en el futuro. La percepción de una amenaza como eminente puede transformar el miedo en terror o pánico.

3 Véase Diccionario de la Real Academia de la Lengua Española, edición 2006.

4 Aristóteles (1985) definía al miedo como la "espera de un mal". cataclismos generados. Después, fue el miedo a las guerras producidas por la disputa de los imperios por territorios y riquezas, ante los efectos devastadores que las confrontaciones bélicas generaban. En tiempos más modernos, bajo regímenes autoritarios $y$ totalitarios, fue el miedo al comunismo, al militarismo y a los gobernantes tiranos, quienes se legitimaban en el poder por el uso de la fuerza y la instauración de una política del terror hacia sus opositores. Hoy, bajo sistemas democráticos, es el miedo a la criminalidad y la violencia, al narcotráfico, a la debacle económica, a la pobreza, a los radicalismos y al terrorismo, entre otros (Valdez, 2009).

Ahora bien, la construcción y el ejercicio del poder político se sustentan, en parte, con base en la movilización de las emociones y sentimientos del ser humano. Ya no se apela a la razón, sino al sentimiento y la emoción de la gente. En este estratagema, el miedo, este verdugo de la creatividad y la libertad social, se ha instituido como un instrumento paradigmático de la política, usado por igual, bajo regímenes tanto autoritarios y totalitarios, como democráticos, ya que el miedo es un instrumento ejemplar de represión, tanto a nivel público como individual (Robin, 2004).

De esta forma, el miedo se ha constituido como una de las políticas de Estado y como instrumento de control y dominación, generando un pueblo atemorizado, indignado y fastidiado. Ante un mundo con más violencia y mayor criminalidad, aumenta más el miedo de los ciudadanos ante la impotencia y la frustración.

Desde la perspectiva psicológica, el miedo es considerado como una de las más antiguas emociones humanas y un factor motivacional, que genera diferentes reacciones psíquicas y conductuales que afectan al sujeto, inhibiéndolo o provocando distintas reacciones. De acuerdo con Manuel Quintanar Diez (1998), 
el miedo es la emoción que se genera ante un peligro eminente (real o putativo), normalmente externo, reconocido como tal por el individuo que lo experimenta.

Marco Tulio Cicerón (1970) consideraba que todo mundo se mantiene en un estado de miedo constante y que el hombre moldea su comportamiento ya sea por la ignominia, la esperanza o por el miedo. Jean Paul Sartre (1978) señalaba que el hombre es, a la vez, miedo y angustia. Finalmente, el ministro de propaganda de Hitler, Joseph Gobbels, solía decir "que muchos tienen un precio y los otros miedo", entronizando el soborno y el terror como política de persuasión nazi.

Además, Doob (1950) señalaba que en afán de lograr la persuasión era necesario apelar en algunos casos al amor, otros al miedo, a la ira, la esperanza o a la culpa.

Para Valdez (2009), el miedo como instrumento de la política, ha sido estudiado por diferentes teóricos del poder. Por ejemplo, Hobbes (1987) consideraba que la sociedad está fundada sobre el miedo y que sin miedo no habría política $^{5}$. De hecho, Hobbes consideraba que la política es una respuesta al miedo. Por su parte, Maquiavelo (1998), en el siglo xvı, consideraba que el miedo es un determinante substancial del comportamiento del ser humano. De ahí que haya aconsejado que es más importante ser temido que ser amado.

La política es un campo en la que el miedo siempre está presente, en sus diferentes manifestaciones, niveles y usos, afectando a diversos grupos e individuos, ya que puede dar lugar a distintas acciones conductuales $y / 0$ a diversas formas de acción evitativas (Valdez, 2007).

De acuerdo con Claudia Hilb (1994), en la relación entre miedo y política se pueden encontrar dos corrientes teóricas centrales: la hobbesiana, que entiende la política como una respuesta al miedo y la otra próxima a Montesquieu, en la que el orden es sinónimo de seguridad. Esta autora afirma que el miedo parece ser

$5 \quad$ Hobbes señalaba que "el miedo que disuade a los hombres de obrar mal no procede el hecho de que se establezcan castigos, sino de que se cumplan. Porque valoramos el futuro por el pasado, y rara vez esperamos lo que rara vez suele suceder". el principio de acción que da forma al vínculo político de las "democracias reales contemporáneas"; es decir, de acuerdo a su concepción, el miedo genera $y$ muchas veces, condiciona o modela, el comportamiento político de los individuos, por lo que es utilizado como estratagema para alcanzar ciertos propósitos, algunas veces perversos, en las democracias modernas.

Al respecto, Rubén Fernández (2006), señala que sí el Estado no tuviese enemigos, tendría que inventarlos. Un Estado sin enemigos temibles (reales o imaginarios) es un Estado débil; pues el poder necesita, por encima de todo, que la población tenga miedo. Mientras que el Estado tenga enemigos, la población vivirá con miedo y cuando la gente tiene miedo, el Estado está a salvo ${ }^{6}$.

Hasta aquí se ha señalado que existen diferentes conceptualizaciones $y$ formulaciones teóricas que afirman que el miedo es una emoción primaria del ser humano, que genera una serie de condicionamientos, actitudes y acciones entre los individuos, lo cual ha sido utilizado históricamente como instrumento de control y disuasión por parte de las elites. A continuación, se describe el uso del miedo en la política y luego en las campañas electorales.

\section{EL MIEDO EN LA POLÍTICA}

El miedo es un gran movilizador de emociones, generando ciertos efectos en la conducta de los individuos, por eso ha sido utilizado exitosamente durante muchos años por los políticos. Mira y López (1957), señalan que el miedo es un testimonio emocional que genera efectos concretos en la conducta del hombre. Por su parte, Ángel Rodríguez Kauth (2004) afirma que el miedo es el gran motor dinamizador de la evolución del hombre. El miedo genera lucha o fuga, en donde algunos

$6 \quad$ En el caso de un conflicto internacional, guerra o invasión, la estrategia del miedo puede ser no tan funcional para el Estado nación. En este caso, resaltar la valentía y el heroísmo del pueblo en gestas históricas que han forjado el carácter de la nación es la estrategia más utilizada. En todo caso, se puede apelar estratégicamente a generar miedo entre las tropas invasora. 
casos, impera el combate $y$ en otros, prima el escape o la huida.

En otras palabras, si el miedo genera efectos e incide en la conducta y comportamiento de la gente, entonces la clase política acude a este artilugio como estrategia para tratar de mantener o alcanzar el poder. De esta forma, el miedo se convierte en la estrategia central para tratar de convencer a las multitudes de que sus adversarios representan ciertos riesgos $y$ pueden generarles distintos daños $y$ perjuicios (Valdez, 2007).

Debido a esta influencia, el miedo ha sido una estrategia antiquísima, relativamente eficaz, usada en la política por distintos líderes y partidos de diferente impronta ideológica, ya que lo mismo lo han utilizado los gobiernos tanto de izquierda como de derecha, como partidos liberales, demócratas o republicanos. La usó Margaret Tatcher en la Gran Bretaña, Ronald Reagan en los Estados Unidos de Norteamérica, el PRI en su época de partido hegemónico de Estado y lo utiliza, también Fidel Castro en Cuba u Ollanta Humala en Perú (Valdez, 2007).

En el caso de México, el Estado utilizó la violencia en 1968 y 1971, en contra de los estudiantes y los líderes sociales para tratar de "pacificar" al país. A través de la apelación al "miedo a la represión", finalmente, los movimientos estudiantiles $y$ populares de esos años fueron desarticulados por las fuerzas represivas.

Ahora bien, existen diferentes tipos y múltiples modalidades del miedo. Por ejemplo, existe el miedo a quedarse sin empleo, el miedo a perder la libertad, el miedo a lo desconocido, a lo diferente, el miedo al escarnio público generado por una derrota electoral, el miedo creado por los altos niveles de inseguridad pública $y$ criminalidad o el miedo a la pobreza, a perder lo que ya se tiene o ha logrado (aunque esto sea poco), entre otros. En este sentido, bien se podría decir que quién posee, teme; temiendo más, el que más tiene. A medida que adquiere bienes, fama y poder, el individuo adquiere también el temor a perderlos y eso conlleva la constante preocupación de velar por su salvaguardia. Solo los más pobres, quienes no po- seen nada o casi nada, no temen ${ }^{7}$ perder lo que no tienen ${ }^{8}$ (Valdez, 2007).

De esta forma, en política la creación de miedo entre los votantes, principalmente los de las clases medias y altas de la sociedad, económicamente hablando, ha sido una estrategia exitosa recurrente durante las campañas electorales ${ }^{9}$. Si se analiza los casos de las últimas campañas presidenciales en Venezuela, Brasil, Bolivia, Perú, Chile y Guatemala, como pasó en México en el 2006, por poner solo algunos ejemplos, se pueden encontrar muchas similitudes de las estrategias $y$ argumentos dados por los candidatos y partidos más conservadores, tratando de evitar que la izquierda asuma posiciones de poder (Valdez, 2007).

\section{EL MIEDO COMO ESTRATEGIA ELECTORAL}

Desde tiempos inmemorables, la creación de miedo entre la población, con fines de control y disuasión, ha sido una estrategia muy común usada en la política. Lo mismo ha sido utilizado en sistemas políticos autoritarios, totalitarios o democráticos. En el pasado, la usaron los romanos, tanto para cohesionar a sus ejércitos ante el peligro de la división interna que los hacía vulnerables o para atemorizar a sus enemigos. Napoleón acudió a la estrategia de simulación de "miedo" para engañar y hacer creer a sus adversarios de su supuesta debilidad militar, lo cual fue utilizado como estrategia de

$7 \quad$ En todo caso, sus temores son otros muchos de origen religioso.

8 Anteriormente, se creía que el miedo era una experiencia solo de los pobres, pero hoy sabemos que esta emoción universal, también afecta a las clases propietarias.

9 Durante el periodo electoral aumenta, generalmente, el nivel de estrés de los empresarios. De acuerdo a la consultora internacional Grant Thornton, de cada 100 empresarios en México, 58 afirmaron sentirse más estresados durante el 2005 en relación al año previo (54). Las razones, fueron el limitado crecimiento económico y la incertidumbre por el escenario político electoral (Periódico Mural. Sección Negocios. Guadalajara, Jalisco, México, 16 de marzo del 2006: p. 6). 
guerra ${ }^{10}$. Después, los usaron los grandes dictadores como Hitler, Mussolini, Stalin y Franco (Reich, 1973 y Lasswel, 1963) para atemorizar a la población e imponer sus decisiones e intereses ${ }^{11}$. Actualmente, bajo sistemas democráticos modernos, se acude también, al artilugio del miedo para ganar votos $y$ acceder a puestos de elección popular ${ }^{12}$. En el 2004, por ejemplo, George W. Bush lo usó como estrategia central de campaña para ganar la elección presidencial en los Estados Unidos de Norteamérica y reelegirse por cuatros años más (Valdez, 2005).

Como instrumento de control, el miedo es una estrategia muy antigua, utilizada no solo por políticos sino también por las diferentes religiones, creando distintos y perniciosos "diablos apocalípticos", de quienes ellos aseguran dar protección o salvación (Valdez, 2007). De esta forma, han logrado afianzar la religiosidad de millones de individuos ${ }^{13}$.

En América Latina, bajo los regímenes dictatoriales del siglo pasado, se impulsó el miedo como política de Estado, para controlar y embelesar a la población. De esta forma, se realizaron verdaderas campañas de terror para hacer que la población se atemorizará a través de diferentes amenazas y hechos represivos (Valdez, 2007). Su propósito fue influir

10 Una estrategia común de Napoleón era aparentar que sus tropas salían huyendo del terreno de batalla en medio del pánico y el terror por el ataque de sus enemigos. Sin embargo, después se volvían $y$ los enfrentaban, tanto por enfrente como a sus espaldas, en forma de pinza, logrando obtener así grande éxitos militares.

11 El miedo ha sido un referente inequívoco usado como estrategia por las elites políticas e incluso, por los movimientos insurgentes. Por ejemplo, durante la revolución francesa, la guillotina representaba el instrumento por antonomasia para generar terror entre los opositores a este movimiento revolucionario.

12 En este sentido, bien se puede decir que la democracia solo ha re-significado el miedo.

13 La mayoría de las religiones utilizan el binomio miedo/salvación como parte de sus estrategias de persuasión. Apelan al miedo al más allá, a sufrir en el infierno y ser torturados por demonios inmisericordes, a no ser que se acojan o busquen protección religiosa para salvarse y evitar el sufrimiento postmorten. o determinar la conducta política de las masas mediante amenazas explícitas o implícitas y actos de terror, como las detenciones, las desapariciones y los asesinatos de luchadores sociales (Baró y Montero, 1987; Garretón, 1988 y Gray, 1986).

En los últimos años, las estrategias del miedo han sido utilizadas en la región, principalmente por la derecha, para tratar de evitar, muchas veces sin éxito, que la izquierda latinoamericana asuma posiciones de poder público. Bolivia, Venezuela, Perú, Brasil, Nicaragua, Costa Rica, Argentina, Uruguay, Chile y Guatemala son solo algunos ejemplos de naciones donde las estrategias del miedo han sido utilizadas recurrentemente, durante las campañas por los grupos más conservadores (Valdez, 2007).

En México, el miedo también ha sido usado como estrategia electoral. Porfirio Díaz (1987), por ejemplo, apelaba a la continuidad y permanencia de su "paz porfiriana", que según decía, había permitido el desarrollo económico y la modernización del país. En tiempos recientes, Ernesto Zedillo Ponce de León ganó arrolladoramente la elección presidencial en $1994^{14}$ explotando el miedo de la población de que la violencia política pudiera generalizarse, después de los arteros asesinatos de Luis Donaldo Colosio ${ }^{15} y$ de Francisco Ruiz Massieu ${ }^{16}$, así como del levantamiento armado de los indígenas en Chiapas ${ }^{17}$.

14 De acuerdo a los resultados oficiales, Zedillo obtuvo el $48,69 \%$ de los votos, Cárdenas el 16,59\% y Diego Fernández de Cevallos del pan el 25,92\% de sufragios.

15 Luis Donaldo Colosio Murrieta era el candidato del PRI a la Presidencia de la República, quien fue asesinado en marzo de 1994, en la ciudad fronteriza de Tijuana, México, durante un acto de campaña.

Ruiz Massieu, asesinado el 28 de septiembre de 1994, fue gobernador del Estado de Guerrero, Secretario General del PRI y Diputado Federal.

17 En enero de 1994, el Ejército Zapatista de Liberación Nacional (EZLN) se levantó en armas enarbolando las banderas de los indígenas chiapanecos en contra de la pobreza y la marginación, además de oponerse al tratado de libre comercio (NAFTA) con los Estados Unidos y Canadá. 
En su momento, Francisco Labastida Ochoa, entonces candidato del pri a la Presidencia de la República, también acudió al expediente del miedo para tratar de evitar que Vicente Fox ganara la elección en el año 2000 (cosa que no sucedió), argumentando que si la oposición conquistaba la presidencia, se generaría un desastre económico, pérdida masiva de empleos, una fuga general de capitales y el cierre de muchas dependencias públicas como el Instituto Mexicano del Seguro Social (imss), Petróleos Mexicanos (pemex), la Comisión Federal de Electricidad (CFE) y el Instituto Nacional de Geografía e Informática (INEGI), entre otros, además de que se pondría en peligro, según decían, la educación pública (cosa que tampoco sucedió).

En la campaña presidencial del 2006, el PAN empleó la estrategia del miedo para ganar la elección, presentando a Andrés Manuel López Obrador (aмLо) como "un peligro para México". De esta forma, el equipo de estrategas de Calderón articuló su campaña con base en la generación de miedo entre la población, lo cual les resultó muy efectiva. Los múltiples spots publicitarios del pan en radio y televisión, así como, las diferentes presentaciones públicas de su candidato, señalaban insistentemente que "si ganaba López Obrador los mexicanos perderían el empleo, la casa y, hasta, el auto, sobreviniendo una crisis económica de magnitudes mayores", como había pasado durante los gobiernos de José López Portillo (1976-1988) y al finalizar el de Carlos Salinas de Gortari (1994). De esta manera, se presentó a amLo como "un peligro para México", quien ahuyentaría la inversión y las oportunidades de desarrollo económico. Además, como pasó en Perú, en la pasada elección presidencial, en la intensa $y$ diversa publicidad política de Calderón, se ligaba despectivamente a López Obrador con el presidente Hugo Chávez de Venezuela, a quien se le señalaba como un gran dictador, causante del creciente empobrecimiento y miseria de su pueblo.

La llamada por los panistas como la campaña de contraste, no fue más que una campaña para influir miedo entre la población, con trazos y argumentos fascistas muy similares a los usados por George W. Bush en la elección de 2004, en los Estados Unidos de
Norteamérica. En esta campaña, los consultores internacionales especializados en campañas negativas jugaron un papel relevante como parte del equipo de Calderón ${ }^{18}$.

$\mathrm{Su}$ estrategia central consistió en generar temor $y$ dudas, principalmente entre las clases medias $y$ altas de la población, para tratar de evitar que apoyaran al candidato de la coalición "Por el bien de todos", quien prácticamente durante la mayor parte del proceso electoral encabezó las encuestas y sondeos sobre preferencias electorales.

\section{4) EL EFECTO EN LA CONDUCTA DE LOS VOTANTES}

Apelar al miedo de los votantes, es una estrategia sumamente rentable, desde la perspectiva electoral, ya que bien gestionadas este tipo de campañas tienen un efecto sumamente persuasivo en la conducta del elector. Al respecto, existen innumerables casos en el orbe de procesos electorales centrados en el miedo que resultaron ser sumamente exitosos.

Uno de estos casos paradigmáticos fue la campaña presidencial centrada en el voto del miedo de Felipe Calderón y el pan, en el 2006. En esta campaña, se presentó a Andrés Manuel López Obrador (amLo), el principal opositor y candidato de la Alianza por el Bien de Todos (de izquierda) conformada por el Partido de la Revolución Democrática (PRD), el Partido del Trabajo (PT) y el Partido Convergencia, como un peligro para México.

De esta forma, se argumentaba (y publicitaba), que la elección de amLo como presidente, provocaría que los capitales internacionales y nacionales se fueran del país, sobrevendría entonces un colapso económico y financiero, y la mayoría de los mexicanos perderían sus bienes, riquezas, empleos y hasta, sus casas y carros. De hecho, generar miedo entre los electores fue el logro principal de este tipo de campaña, misma que redujo la ventaja de amLo de 10 puntos porcentuales en

18 Por su parte, Madrazo, se unió a la campaña del miedo que impulsó el PAN para denostar y agredir a López Obrador, señalando que con el advenimiento de un gobierno populista, los mexicanos ponían en riesgo su desarrollo económico y bienestar. 
las preferencias electorales sobre su principal opositor (Felipe Calderón). Al final, las autoridades electorales reconocieron el triunfo de Calderón con una diferencia de $0,58 \%$ de votos (Valdez, 2009).

De acuerdo con Juan Camilo Mouriño $0^{19}$, uno de los coordinadores de la campaña de Felipe Calderón, "esta campaña de contraste, como la llamaron los panistas, permitió reducir en seis o siete puntos la ventaja del candidato del PRD. Es decir, cerca de tres millones de votos" (Castillo, 08/08/2006).

En el mismo sentido, una investigación realizada por académicos de la Universidad Nacional Autónoma de México sobre esta elección, determinó que:

... las campañas negativas sí tuvieron efectos en el electorado. Entre los votantes que señalan que en su decisión de voto influyeron las afirmaciones de que López Obrador es un peligro para México, el 52.2\% votó por Felipe Calderón y solamente el $17.34 \%$ lo hizo por amLo. Entre los ciudadanos que se vieron influidos por las acusaciones sobre el cuñado de Felipe Calderón, el $56.6 \%$ votó por amLo y solamente el $20.5 \%$ lo hizo por Felipe Calderón (Buendía y Bustos, 03/07/2006).

\section{5) SU ARTICULACIÓN ESTRATÉGICA DURANTE LAS CAMPAÑAS}

Toda campaña electoral exitosa, articula sus estrategias no solo con base en sus propuestas, ideas y proyectos de nación, sino también tomando en consideración la movilización de las emociones (principalmente, el miedo) de los electores (Valdez, 2009). Por un lado, miedo a que las cosas empeoren, a que se pierda lo que se tiene, se atente en contra del sistema de valores y creencias establecidas; es decir, la estrategia electoral se centra en comunicar y hacer sentir a los votantes que si los opositores llegan

19 Juan Camilo Mouriño fue secretario de gobernación en México, el segundo puesto en el gobierno federal después del Presidente de la República. Murió en un accidente aéreo en noviembre del 2008. al poder, destruirán, acabarán y amenazarán tanto el sistema de creencias, valores o propiedades $y$ generarán problemas a la estabilidad y el confort que hasta ahora se tiene, poniendo en riesgo el futuro del país.

Apelar al miedo es propio - aunque no exclusivo- de campañas electorales de partidos en el poder y también lo hacen los partidos y candidatos que están en la oposición.

El voto del miedo parte de un modelo muy sencillo. Primero, se analizan cuáles son los temores, amenazas, riesgos, preocupaciones, miedos y peligros más sentidos y percibidos por los electores, como pueden ser los casos del miedo al terrorismo, a la debacle económica o a la criminalidad. Segundo, se priorizan los temores $y$ se determina la forma en que puede ser planteado, electoral $y$ estratégicamente hablando. Tercero, se evalúa $y$ determina la experiencia que los electores han tenido en procesos electorales pasados respecto de estos temores prevalecientes, con el fin de determinar la pertinencia, la modalidad y la oportunidad del planteamiento estratégico. Cuarto, como parte de la estrategia publicitaria, se presenta la situación temible como algo que requiere una especial atención, debido a que el futuro depende de la superación de esa amenaza. Quinto, se vincula a los opositores con los riesgos y peligros presentes en la coyuntura electoral, los cuales han sido percibidos y catalogados en importancia por los electores. Sexto, se presenta la alternativa propia como la única que garantiza proveer una solución eficaz a la amenaza. Séptimo, se evalúa el efecto de la campaña y su cobertura mediática en la conducta y el comportamiento de los electores. Octavo, se realiza una retroalimentación del proceso y en caso necesario, se hacen las adecuaciones $y$ mejoras pertinentes.

Al impulsar este tipo de campañas, es importante tomar en consideración la credibilidad de las fuentes informativas y la cobertura mediática que se haga de la misma. También, es pertinente cuidar que este tipo de campañas no genere el efecto bumerán, porque al no lograr la gestión adecuada, los resultados pueden ser contraproducentes para sus impulsores (Valdez, 2009). 
Hoy, las estrategias proselitistas centradas en el miedo son muy utilizadas, tanto por partidos de derecha como de izquierda. Por ejemplo, durante la elección primaria para nominar al candidato a presidente de los Estados Unidos de Norteamérica en el 2008, por el Partido Demócrata, Hillary Clinton apeló al miedo como estrategia política cuando señaló que "la red terrorista Al Qaeda vigila las elecciones estadounidenses. ¡No corramos el riesgo de elegir a un presidente sin experiencia! ${ }^{20}$ (Valdez, 2009).

Sin embargo, este tipo de campañas también pueden ser utilizadas por la izquierda. De hecho, varios candidatos a la presidencia postulados por partidos de izquierda, en distintos países de América Latina, han centrado su estrategia en explotar los temores $y$ fobias de los electores. Su argumento central se nutre de los siguientes razonamientos: de llegar la derecha al poder, se perderán las prestaciones laborales y las conquistas sociales; se entregarán los recursos naturales y estratégicos a las empresas multinacionales; se pondría en riesgo el estado laico; aumentará la corrupción, el desempleo, la inseguridad pública y el aumento de los precios a productos básicos (leche, tortilla, gasolina, etc.); se pondría en riesgo la educación pública y se conculcarán las libertades democráticas (se criminalizará la protesta social y se atentará en contra de las garantías constitucionales) ${ }^{21}$ (Valdez, 2009).

$20 \quad$ Clinton se estaba refiriendo a Obama, a quien acusó de no tener la experiencia suficiente para el cargo de Presidente de la República y Comandante en Jefe de las fuerzas armadas de los Estados Unidos de Norteamérica.

21 En febrero de 2009, Hugo Chávez apeló a la estrategia del miedo en el referéndum, donde se determinó la reelección indefinida en Venezuela. Su campaña estuvo centrada en el argumento de que "Chávez es una garantía de paz social para Venezuela, ya que sin Chávez habría caos". En el 2011, Ollanta Humala también apeló al miedo de los electores peruanos a los sistemas autoritarios $y$ represivos como el de Alberto Fujimori. Durante su campaña, Humala señaló que Keiko Fujimori representaba el regreso al pasado autoritario, la violación a los derechos humanos, la corrupción y la violencia política que representó su padre Alberto Fujimori.
En fin, el voto de miedo es una estrategia política ampliamente utilizada durante las campañas electorales. Este tipo de estrategias se inscribe dentro de lo que se llama las campañas negativas, mismas que parten del principio de que es posible incrementar el interés, la atención y la persuasión de un anuncio, a través de la apelación al miedo (Snipes, La Tour y Bliss, 1999) y de que los anuncios con alto contenido emocional originado por una amenaza, tienen efectos más profundos y duraderos en el cambio de actitud, los cuales están vinculados con la conducta (Sternthal y Craig, 1974).

\section{6) CONTRAESTRATEGIAS PARA ENFRENTAR EL MIEDO}

Hasta aquí, se ha comentado que las elites políticas acuden a la táctica del miedo para tratar de alcanzar o conservar el poder. También se ha dicho, que no importa el tipo de sistema político prevaleciente, puesto que prácticamente en todos se apela al miedo para tratar de alcanzar sus objetivos políticos. Sin embargo, es importante decir que en toda sociedad existe también, diferentes mecanismos e instrumentos para tratar de palear o reducir el impacto del miedo entre diferentes sectores de la población. A continuación se describen los efectos que el miedo ocasiona entre los electores, así como, las diferentes contraestrategias que se pueden impulsar para minimizarlos o revertirlos.

Como se ha señalado, el miedo es una emoción generada por la percepción de un peligro próximo, real o imaginario, que va siempre acompañado por un vivo deseo de evitarlo y de escapar de la amenaza. Esto es, todo temor genera ciertas pautas de conducta y motiva al hombre a tomar ciertas decisiones y determinaciones. Si se es exitoso en generar miedo entre la población, los efectos que este puede generar en la conducta de la gente, durante un proceso electoral, son los siguientes:

$\diamond \quad$ El miedo provoca, de manera natural e inconsciente, desconfianza y un conflicto potencial con las fuentes causantes de las amenazas. Se impone así una visión binaria de la realidad: los buenos $y$ los malos, los que nos protegen y los 
que nos amenazan. Es decir, el miedo nos genera desconfianza, rechazo y oposición hacia unos (los que amenazan) y simpatía, afecto y solidaridad hacia otros (los que protegen).

$\diamond \quad$ El miedo crea un dominio absoluto de las emociones en nuestras relaciones con los otros, así como respuestas emocionales condicionadas a los acontecimientos políticos. De esta forma, los sujetos no solo son obligados a rechazar y evitar al otro, representante de la amenaza, sino incluso a oponerse $y$ luchar para tratar de que no se imponga como paradigma. Esto es, el miedo es el principal reclutador de distintos activistas dándoles energía y razones para que se opongan abiertamente a quienes ellos perciben como amenaza.

$\diamond \quad$ En procesos electorales, el miedo provoca que más individuos participen en los comicios, ya que si no se participa "se pueden imponer los que amenazan"; es decir, el nivel de conflicto social que perciben los votantes durante la campaña $y$ lo que consideran está en juego, como su seguridad $y$ prosperidad, son elementos determinantes y motivadores de una mayor participación política.

$\diamond \quad$ El miedo genera antipatías, fobias, animadversiones e incluso, odios políticos, ya que cuando el miedo se impone, las emociones minan cualquier posibilidad de análisis racional.

$\diamond \quad$ Ahora bien, es posible desactivar el impacto de las estrategias y tácticas impulsadas para crear miedo entre los votantes, para lo cual sobresalen las siguientes alternativas:

$\diamond \quad$ La visualización ayuda a desmantelar la estrategia del miedo. Esto es, como emoción, al ser "descubierto," el miedo tiende a desaparecer o equilibrarse. Si los afectados por una campaña del miedo denuncian ante la opinión pública y pueden dar evidencias creíbles de que el miedo es una estrategia planeada e impulsada por sus contrincantes solo para manipular a los electores, al ser descubierto dicho montaje, su efecto persuasivo se reduce o incluso, puede revertirse en contra de sus impulsores ${ }^{22}$ (Valdez, 2007).

$\diamond \quad$ El miedo puede ceder a una contracampaña de miedo o terror más creíble, intensa y poderosa. Por ejemplo, si una estrategia de un candidato o partido político determinado está orientada a generar miedo entre la población sobre las posibles consecuencias que puede generar un mayor aumento de la criminalidad si sus contrincantes arriban al poder, esta campaña puede ser revertida si en ese momento se presentan actos terroristas ${ }^{23}$ sumamente desastrosos que el gobierno en turno no pudo evitar ${ }^{24}$; es decir, la estrategia del miedo es combatida por los opositores con una contra-estrategia que finalmente, genera un miedo más intenso entre la población (Valdez, 2007).

22 Esto pasó en la elección nicaragüense a inicios de la década de los 90 , cuando los sandinistas publicitaban que de ganar la Unión Nacional Opositora (UNO), encabezada por Violeta Barrios de Chamorro, las conquistas de la revolución se perderían, la guerra civil se recrudecería y el imperio americano volvería a reinar en ese país. Sin embargo, Violeta Barrios exitosamente denunció que el ESLN estaba orquestando una campaña para generar miedo entre la población y así ganar la elección presidencial. Al final, la UNo no solo ganó la elección presidencial obteniendo un $54,7 \%$ de los votos, sino que además obtuvo 51 de 92 escaños en la Asamblea Nacional de Nicaragua.

23 En toda contienda electoral, no se descarta la posibilidad de realizar actos que atemoricen a la población, incluyendo asesinatos políticos y atentados, que finalmente sean manipulados por sus propios perpetradores para efecto de ganar la contienda electoral.

24 Esto pasó, de cierta manera, en España, cuando el candidato del Partido Popular, Mariano Rejoy, se presentaba como la mejor alternativa de gobierno para hacer frente al grupo terrorista ETA. Sin embargo, ante los atentados al sistema de transporte público español por parte del grupo Al Qaeda, los votantes sintieron más temor y al ser descubierta la manipulación de la información sobre los presuntos responsables de las explosiones en la estación del tren de Atocha en Madrid, que quería hacer el presidente José María Aznar, muchos electores terminaron votando por Rodríguez Zapatero, candidato del Partido Socialista Obrero Español, quien finalmente ganó la elección. 
$\diamond \quad$ La estrategia del miedo puede ser desmantelada presentando evidencias creíbles $y$ contundentes de su falsedad, atacando de esta forma, la estrategia del adversario. Por ejemplo, si un candidato o político señala que su opositor se opone a los empresarios, al libre comercio y la inversión externa, pero este adversario le responde con una agresiva campaña publicitaria en medios de comunicación, en la que muestra diferentes testimonios de empresarios e inversionistas apoyándolo y señalando que creen en su proyecto de gobierno $y$ apoyan su candidatura, finalmente la estrategia original del miedo no surte los efectos esperados o bien, estos son contrarrestados ${ }^{25}$.

$\diamond \quad$ La estrategia del miedo puede ser revertida fácilmente ${ }^{26}$, cuando la credibilidad $y$ confianza de los ciudadanos, respecto a los que detentan el poder y por lo tanto, impulsan la campaña del miedo, es muy baja. La gente tiende, en estos casos, a creerle y apoyar inversamente a quienes son objeto de crítica o presentados por parte de malos gobernantes como los que amenazan. El razonamiento es muy sencillo: sí no lo quieren y lo atacan los que la ciudadanía considera como "malos", entonces se piensa que son buenos, por lo tanto, hay que apoyarlos (Valdez, 2007).

25 Esto es lo que tendría que hacer AmLo, a través de una campaña en medios de comunicación en las que un grupo de empresarios reconocidos $y$ prestigiados, le muestran su apoyo y señalan que sus inversiones y proyectos empresariales crecerán durante su gobierno.

En el caso de la campaña presidencial de 2006, López Obrador, en un primer momento, no quiso apostarle a la campaña negativa $y$ a otras estrategias para desarticular la campaña de miedo de la que fue objeto. En un segundo momento, casi al finalizar la campaña, acusó a Felipe Calderón de tener un cuñado (Diego Hidelbrando Zavala) que se había beneficiado por contratos en la Secretaría de Energía del gobierno mexicano por más de 2500 millones de pesos y por los cuales no había pagado ningún impuesto. Sin embargo, al final el tiempo no fue suficiente para que AMLO pudiera revertir la tendencia electoral. $\diamond \quad$ Se pueden impulsar campañas intensas en medios de comunicación donde se resalte el espíritu de valentía y arrojo que caracteriza a los electores y recalcando que nadie los va a atemorizar con el "petate del muerto", convocando a los votantes a tener el valor para enfrentar el desafío del cambio en el gobierno. Recuérdese que el valor (tener valor) es una cualidad moral que mueve a los hombres a acometer, resueltamente, grandes empresas y a superar, sin miedo, los peligros ${ }^{27}$ (Valdez, 2007).

\section{7) VOTAR CON MIEDO: ELECCIONES PRESIDENCIALES EN MÉXICO 2006}

Como dice Paul Virilio (2005), el miedo es el argumento y la estrategia central de la política moderna. Lo que hicieron los candidatos y partidos en México, de cara a la pasada elección presidencial de 2006, fue acuñar y difundir mensajes que crearon miedo, generando de esta manera, un estímulo sensible que fue percibido por los electores y que generaron una respuesta condicionada, al estilo Pavlov ${ }^{28}$.

Como estrategia política, el miedo fue utilizado durante la campaña presidencial de 2006 en dos grandes vertientes, aunque de forma un tanto articulada. Por un lado, como instrumento para generar temor, cuestionar certezas, generar sospecha $y$ producir dudas entre los votantes para que estos rechazaran y se opusieran a Andrés Manuel López Obrador (aмLо). De esta forma, los panistas afirmaron que aмLо era el candidato que representaba la violencia, el populismo, la demagogia, la corrupción, el "es-

27 Quien vota, consciente e inconscientemente, en una determinada dirección por miedo, no puede ser responsable, políticamente, de los gobiernos que genera. De lo único que se le puede culpar moralmente, es de ser fácilmente manipulado y de no tener el valor suficiente para vencer la resistencia al cambio.

28 De acuerdo a Ted Brader (2004: 39), la ansiedad producida por los anuncios publicitarios que generan miedo, juega un papel muy importante en la política. De ahí que la propaganda negativa sea también persuasiva. El miedo como emoción es un elemento central en muchos de los spots políticos y sus efectos en la conducta de los electores durante las campañas, pueden ser desastrosos. 
pantachambas" y el desastre económico del país, dañando de esta forma, su reputación y generándole una identidad negativa ${ }^{29}$. De acuerdo a esta estrategia, amLo era el candidato a vencer ${ }^{30}$.

Por otro lado, ante un contexto de alta inseguridad prevaleciente en el país, los panistas utilizaron el miedo como referente estratégico para que los votantes vieran en ellos la mejor alternativa de gobierno que les ofrecía seguridad, sea esta pública, jurídica, social o económica. En este sentido, bien se puede conjeturar que ganó la Presidencia de la República, quien mejor logró transmitir a los electores un sentimiento de seguridad ${ }^{31}$, respecto a los temores reales o imaginarios más generalizados existentes entre los mexicanos ${ }^{32}$.

Los panistas apelaron a la estrategia del miedo como vía de impacto en la conducta electoral y de movilización de emociones, tratando de tocar cuerdas sensibles de los votantes. La

29 Por ejemplo, en el Estado de Hidalgo, el 16 de marzo de 2006, Josefina Vázquez Mota, coordinadora de la campaña de Calderón, señaló ante una reunión de empresarios: "los invito a que se terminen de espantar [con López Obrador] o de animar [con Calderón]". Por su parte, el abanderado presidencial panista señaló "AmLo lleva una campaña en la que siembra el odio entre los mexicanos y esa es una irresponsabilidad, por eso él representa un peligro para el país".

30 Al respecto, Hans Jonas señala en lo que denominó la "heurística del miedo", que la acción política consiste en tomar nota de los peligros. En este sentido, los contrincantes y opositores de AMLO, entre los cuales se puede ubicar también a un sector de la prensa conservadora como el Grupo Radiofónico Imagen, las revistas Siempre y Contenido, así como, algunos analistas políticos, como es el caso de Jaime Sánchez Susarey.

31 En el caso mexicano, la inseguridad es entendida en dos grandes variantes. La primera, como el temor entre las clases medias y altas de la sociedad de "perder o arriesgar" lo que se tiene, aunque sea poco, como la paz social, la estabilidad macroeconómica, el gozar de cierto bienestar económico, tener empleo y varios servicios públicos como educación y salud. La segunda, entendida como la falta de garantías por la inseguridad que representa los altos índices de delincuencia y criminalidad que prevalecen en el país.

32 La seguridad no solo entendida como defensa ante posibles ataques a lo establecido o logrado, sino la que garantice un mejor desarrollo futuro integral para los individuos. política del miedo consistió en crear entre los ciudadanos el temor de que ambo, de llegar a ser electo, dañaría sus intereses económicos, destruiría su sistema de valores $y$ afectaría sus propiedades o posibilidades de desarrollo futuro ${ }^{33}$. Se decía, que de llegar aмьo al poder, regresarían las crisis económicas, se elevaría el endeudamiento externo y que México se precipitaría al abismo.

De esta forma, los miedos a los que apelaron los partidos y candidatos en la pasada elección presidencial fueron principalmente, el miedo al populismo ${ }^{34}$, el miedo al cambio ${ }^{35}$, el miedo a la demagogia ${ }^{36}$, el miedo al pasa$\mathrm{do}^{37}$, el miedo a los radicalismos ${ }^{38}$, el miedo a la violencia ${ }^{39}$, el miedo a las crisis económicas

33 Apelar al miedo de los votantes es una estrategia principalmente de los partidos gobernantes. En la elección mexicana de 1994, se usó el miedo como principal estratagema por parte del PRI para derrotar a sus adversarios, principalmente los de izquier$\mathrm{da}$, aprovechando ciertos errores por parte de los perredistas, ya que el PRD imprimió un cartel que mostraba a su candidato presidencial, Cuauhtémoc Cárdenas, saludando al sub-comandante Marcos, principal dirigente del EzLN. Esa propaganda, que lo identificaba con el EzLN, más que ayudarlos, le restó muchos votos, principalmente, entre las clases medias. En la pasada elección, el PAN para mantenerse en el poder, usó la misma estrategia del miedo que utilizó el PRI, cuando este ocupaba la titularidad del Poder Ejecutivo Federal.

34 El miedo al populismo, entendido como una política que da limosnas, pero genera más pobreza.

35 Se decía: si las cosas están bien y hay estabilidad económica y financiera, para qué arriesgar a cambiar de gobierno.

36 Consistió en generar temor ante líderes carismáticos como AMLO, que lucra políticamente hablando, según dicen, con la pobreza de los mexicanos. De acuerdo a esta concepción, los demagogos son los que prometen mucho $y$ hacen poco.

$37 \quad$ Miedo a regresar a estadios traumáticos para los mexicanos.

38 El temor de que se impusiera un gobierno radical, como el de Hugo Chávez en Venezuela, que genere cambios drásticos y afecte el interés de mucha gente.

39 Consistió en equiparar a AMLO y al PRD con un partido de "tribus" y grupos que privilegian la violencia como forma de hacer política. 
(desempleo $)^{40}$, el miedo a la corrupción ${ }^{41}$, el miedo al autoritarismo ${ }^{42}$, así como, el miedo a la ingobernabilidad e inestabilidad ${ }^{43}$.

El candidato objeto principal de acometida por estas estrategias fue amLo, considerando que sus opositores fueron relativamente exitosos, al generar ciertos temores y dudas sobre el futuro económico de la nación ${ }^{44}$, entre amplios sectores de la sociedad, principalmente, entre las clases medias y altas (Valdez, 2006).

En esta cruzada por generar miedo entre la población y así generar efectos en la conducta $y$ decisión de los votantes, los principales impulsores de estas estratagemas contra amLo, no solo fueron los otros candidatos y partidos opositores, a través de sus recurrentes spots publicitarios, cibercampañas, entrevistas en medios de comunicación y presentaciones públicas (mitines y reuniones), sino también la jerarquía de la Iglesia católica, las cúpulas empresariales, un sector de intelectuales y periodistas conservadores, el propio presidente entonces en funciones (Vicente Fox) ${ }^{45}$, así como, ciertos personajes ligados a los intereses de los Estados Unidos de Norteamérica.

40 Miedo a perder lo que se ha logrado y arriesgar el patrimonio de los electores, regresando a la etapa de crisis económicas y devaluaciones abruptas del peso con respecto a otras monedas.

41 Este tipo de miedos lo asocian con los abusos y corruptelas del pasado, que se han estereotipado como propias de los candidatos priístas.

Miedo a regresar a estadios predemocráticos, donde las libertades civiles, políticas y económicas sean conculcadas.

43 El miedo al desgobierno que afecta el desarrollo y progreso de la gente.

44 Al respecto, Felipe Calderón señala, por ejemplo, que AMLO confronta y divide a los mexicanos con su discurso clasista, aspecto superado en la historia de la humanidad y que será, en caso de que gane la elección, el presidente "espanta-chambas", ya que no solo la inversión no llegará, sino que la existente se retirará.

El presiente Vicente Fox, con sus declaraciones a los medios de comunicación y constantes ataques a lo que él llama el populismo y los emisarios del pasado, lo que realmente está impulsando es una especie de campaña de Estado, usando recursos públicos y la envestidura presidencial, con el fin de generar miedo entre los electores $y$ así estos no apoyarían a la izquierda ni a su candidato, como una alternativa de gobierno.
Al final, amLo y su equipo de campaña no supieron desarticular las estrategias del miedo, perdiendo la ventaja de más de diez puntos porcentuales que tenían.

\section{8) COMENTARIOS FINALES}

El miedo es uno de los instintos y emociones más primitivas, poderosas e incontrolables del ser humano, que las elites han utilizado como parte de sus estrategias para el control político (Valdez, 2009), bajo regímenes autoritarios y totalitarios se apeló al miedo de la gente para dominar a los opositores y mantener el poder político, económico y militar. Actualmente, bajo regímenes democráticos, se sigue apelando al miedo y a la ira como estrategia para ganar elecciones.

El miedo ejerce en el hombre un gran poder de persuasión y movilización. Por miedo se hace o se evita hacer muchas cosas. En una sociedad democrática, sustentada en el voto mayoritario de los electores, ganará o conservará el poder quien sea más competitivo en el estudio, comprensión y manejo de este tipo de emoción (Valdez, 2009).

El crear miedo es una estrategia añeja de los políticos, la cual actualmente, es utilizada por diferentes partidos y candidatos durante los procesos electorales, debido a la vulnerabilidad emocional del ser humano y a los efectos que esto genera en su conducta. De hecho, se puede asegurar que las actuales campañas electorales en el mundo se articulan, de una u otra forma, con base en la generación e institucionalización del miedo ${ }^{46}$. Por un lado, miedo a que las cosas empeoren y se pierda lo que se tiene o ha logrado, o que se amenace el sistema de creencias y valores predominante. Por el otro, como garantía de seguridad pública, militar, económica, jurídica o social, así como, salvaguarda ante las amenazas y peligros, reales o imaginarios, existentes ${ }^{47}$.

$46 \quad$ El caso de la elección para gobernador celebrada el 13 de noviembre de 2011, es un ejemplo de cómo el miedo es usado como parte de las estrategias por parte de los partidos y sus candidatos.

47 El objetivo central de estas campañas de miedo fue que los electores vieran $y$ asumieran que los adversarios de ciertos partidos y candidatos, también eran sus adversarios, quienes los amenazaban y les pueden hacer algún daño o mal. 
En una sociedad democrática, ganará el poder el individuo o grupo de individuos que mejor gestione, aproveche $y$ articule o desarticule, según sea el caso, las estrategias del miedo. Aquellos políticos más capaces de movilizar las emociones de la gente y que hagan que los votantes teman, rechacen y luchen contra los adversarios de los propios políticos, haciendo creer a los ciudadanos que son sus propios adversarios. También, los que convenzan o aparenten, de cara a la sociedad, ser más aptos y capaces para combatir la inseguridad pública $y$ dotar de garantías de estabilidad, bienestar y desarrollo futuro a los electores ${ }^{48}$.

En América Latina, existen muchos ejemplos de campañas presidenciales que basaron su estrategia en la movilización de esta emoción. El caso de México en el 2006, sustentada en el voto del miedo en contra de López Obrador es paradigmática.

De sus resultados, se infiere que el miedo genera grandes efectos en la conducta del votante. En primer lugar, refuerzan predisposiciones ya existentes en la mente y corazón de los ciudadanos, a favor o en contra de ciertas opciones políticas. En segundo lugar, generan también la activación de algunos electores, quienes no pensaban participar en los comicios, pero que finalmente, producto de las campañas de miedo, deciden participar a favor o en contra de una determinada opción política. En tercer lugar, logran convertir a algunos electores quienes pensaban votar por una opción, pero terminan haciéndolo por otra. Finalmente, este tipo de campaña logra desactivar también, a muchos electores, quienes pensaban participar en los comicios pero al final, no lo hacen (por temor).

En el futuro, como lo fue en el pasado, el poder lo tendrán aquellos políticos e institutos más capaces de movilizar el miedo de los votantes. Por un lado, el miedo a que se pierda lo logrado o se empeoren las cosas. Por el otro, el miedo generado por la inseguridad pública y el alto nivel de criminalidad. En fin, es el miedo lo que moviliza a los votantes $y$ hace ganar o perder elecciones (Valdez, 2009).

$48 \quad$ Como lo señala Reguillo (2000): "el miedo es una experiencia individualmente experimentada, socialmente construida y culturalmente compartida".

\section{BIBLIOGRAFÍA}

Aristóteles. Ética a Nicomaco. Clásicos políticos. Edición bilingüe por María Araujo y Julián Marías. Madrid, España: Centro de Estudios Constitucionales, 1985.

Baró, I. M. y Montero, M. (eds.). Psicología politica latinoamericana. Caracas, Venezuela: Panapo, 1987.

Bayardo Pérez Arce, Alberto. Anulando el voto en México. La mercadotecnia de una alternativa política. México: Iтeso, 2009.

Brader, T. Campaigning for hearts and minds: how emotional appeals in political ads work. New York, usa: University Press, 2004.

Buendía, Jorge y Bustos, José Luis. "Campañas negativas sí influyeron”. El Universal. 03 de julio de 2006.

Castillo, Eduardo. "La campaña negra que le restó votos a López Obrador". The Associated Press. 8 de agosto de 2006.

Cicerón, M. T. De legibus. Madrid: Instituto de Estudios Políticos, 1970.

Díaz, P. "Krauze, Enrique: Porfirio Díaz, místico de la autoridad". Serie Biografía del Poder. México: Fondo de Cultura Económica, 1987.

Doob, Leonard W. "Goebbels' Principles of Propaganda". The Public Opinion Quarterly 14 (3). Oxford University PressAmerican Association for Public Opinion Research, 1950: 419-442. En: http:// campus.murraystate.edu/faculty/mark. wattier/Doob1950b.pdf [consultado el 30 de octubre de 2013].

Fernández, Rubén. "La política del miedo". El Libertario. Noviembre-diciembre 2004: 15. En: www.nodo50.org/ ellibertario/40rubenf.htm [consultado el 16 de abril de 2006].

Garretón, Manuel Antonio. "El miedo y las dictaduras militares". Revista Mensaje 371. Santiago, Chile. Agosto 1988: 30-42.

Gray, J. A. "Miedos innatos y adquiridos". Psicología ciencia y conciencia. Ignacio Martín Baró. San Salvador, El Salvador: Universidad Centroamericana "José Simeón Cañas" (UCA), 1986. 
Hilb, C. "Promesa y Política. Promesas traicionadas y transición democrática". Textos de Jóvenes Investigadores. Buenos Aires, Argentina: Facultad de Ciencias Sociales-Secretaría de Investigación, 1994.

Hobbes, T. Del ciudadano y leviatán. Enrique Tierno Galván y M. Sánchez Sarto (trads.). Madrid, España: Editorial Tecnos, 1987.

Lasswell, Harold. Psicología y Política. Buenos Aires, Argentina: Paidós, 1963.

Lira, Elizabeth. Psicología de la amenaza política y el miedo. Chile: Instituto Latinoamericano de Salud Mental y Derechos Humanos (ILAS), 1991.

Maquiavelo, N. El Príncipe. Madrid, España: Prometeo Libros, 1998.

Mira, Jorge y López, Emilio. Manual de Psicología Política. 1era. edición. México: Editorial Salvat, 1957.

Pavlov, I. P. Reflejo condicionado. uRss: Academia de Ciencias, 1927.

Quintanar, Manuel. La eximente de miedo insuperable. Madrid, España: Editoriales de Derecho Reunidas (eDERSA), 1988.

Reguillo, Rossana. "La construcción social del miedo. Narrativas y prácticas urbanas". Ciudadanías del miedo. Susana Rotker (ed.). Venezuela: Nueva Sociedad, 2000.

Reich, W. (1973). Psicología de masas del fascismo. México: Ed. Roca, 1998.

Robin, C. Fear: the history of a political idea. New York, eeuu: Oxford University Press, 2004.

Rodríguez, Ángel. "El miedo, motor de la historia individual y colectiva". Revista Crítica de Ciencias Sociales y Jurídicas. Madrid, España: Universidad Complutense de Madrid, 2004.

Sartre, Jean Paul. La trascendencia del ego. Colombia: Editorial Síntesis, 1978.

Snipes, R.; La Tour, M. y Bliss, S. "A model of the effects of self-efficacy on the perceived ethicality and performance of fear appeals in advertising". Journal of Business Ethic 3 (19). 1999: 273-285.

Sternthal, B. y Craig, S. "Marketing experimentation". Marketing research: fundamentals and dynamics. G. Zaltman y P. Burger. Michigan, eeuu: Dryden Press, 1974.

Valdez, Andrés y Huerta, F. D. Anulando el voto en México. La mercadotecnia de una alternativa política. México: Iтеso, 2009.

Valdez, Andrés. "¿Cómo salir exitoso de una campaña negativa?". E-lecciones. 7 de julio de 2007. En: <http://e-lecciones.net/ opinion/?numero $=459 \&$ show $=1 \& \mathrm{p}=\mathrm{d}>$ [consultado el 15 de febrero de 2012].

Valdez, Andrés. "El uso del miedo para ganar campañas". Gaceta de la Universidad de Guadalajara. 25 de mayo de 2009. En: <http://gaceta.udg.mx/G_nota1. php?id=5214> [consultado el 20 de septiembre del 2013].

Valdez, Andrés. "La estrategia del miedo en las campañas electorales: la elección presidencial en México, 2006". Este país 183. 2006: 30-34. En: <http://estepais. com $/$ site $/ ? \mathrm{p}=21311$ \#sthash.11GbHz7P. dpuf $>$ [consultado el 10 de octubre del 2013].

Valdez, Andrés. "Opinión pública y campañas electorales: los resultados de las elecciones en los Estados Unidos, una decepción para el mundo". Revista Ámbitos 13-14. Sevilla, España. Facultad de Comunicación, Universidad de Sevilla, 2005.

Virilio, P. Ville Panique. París, Francia: Editorial Galilée, 2005.

Fecha de ingreso: 01/02/2012 Fecha de aprobación: 14/01/2014 